\title{
Relaciones de género emergentes y paternidad en el hacer familia dentro de contextos Homoparentales
}

\author{
Emerging gender relations and paternity in family making within \\ Homoparental contexts
}

Marcelo Robaldo*

\begin{abstract}
Resumen
El presente artículo presenta los resultados de la investigación titulada Relaciones de género emergentes en el hacer familia dentro de contextos Homoparentales, realizada para el Master de Equidad Igualdad en el Desarrollo de la Universidad de Vic, España. Aborda las relaciones inter-género dentro de contextos de homoparentalidad. Se parte de la noción que las personas no heterosexuales pueden compartir una realidad comunitaria que los vincula solidariamente frente a la exclusión y por ende las lleva a "hacer" parentalidad de un modo reflexivo - hablamos aquí de la parentalidad como un "hacer" performativo tal como lo plantea Judith Butler-. Un modo de hacer parentalidad que no es "natural" y que conlleva negociaciones, acuerdos y compromisos que lo diferencian respecto de una construcción del parentesco hecha en sintonía con el contexto cultural y social de la heteronormatividad.
\end{abstract}

Palabras claves: Relaciones de género, Homoparentalidad, Maternidad, Cuerpo Reproductivo, Parentalidad.

\begin{abstract}
This article briefly presents research results of the study entitled Doing family in homosexual kinship contexts and emergent gender relations, carried out for the Masters program in

\footnotetext{
* Sociólogo, Master en Igualad y Equidad en el Desarrollo, Universidad de Vic, España. Profesor del Magister en Estudios de Género y Cultura en América Latina, Universidad de Chile.

Nota biográfica: Obtuve el título de Sociólogo profesional de la Universidad de Chile el año 2000. Luego cursé el diplomado de Crítica Epistemológica Feminista de la Universidad Nacional Autónoma de México. En 2016 obtuve el grado de Master en equidad e igualdad en el Desarrollo de la Universidad de Vic, España. Desde 2007 he sido integrante del Núcleo de Estudios de Género y Sociedad Julieta Kirkwood y miembro del comité editorial de la revista académica Punto Género,
} ambos de la Universidad de Chile.
\end{abstract}


Gender Equality in Development of the University of Vic, Spain. The article deals with inter gender relations within homosexual parenting contexts. It's central assumption is that non heterosexual individuals may share a community bond that springs from their experience of exclusion, which in turn defines their forms of doing family as a reflexive project - doing family here is understood as performative, following Judith Butler's view of homosexual kinship. It is an "unnatural" form of kinship which entails commitments, negotiations and agreements, all of which make it distinct from kinship performed in accordance to a heterosexual and heteronormative social and cultural context.

Key words: Gender relations, Homosexual kinship, Maternity, Reproductive body, Parenting.

Fecha de recepción: 29 de mayo 2017

Fecha de aprobación: 30 de mayo 2018

\section{Introducción}

Las mujeres y hombres no heterosexuales que hacen familia enfrentan desafíos frente a la procreación que son inherentes a su condición de parejas del mismo sexo. Pero, además, enfrentan barreras que provienen de los prejuicios y la discriminación propios de la homofobia. Para ambas cuestiones estos hombres y mujeres han encontrado maneras solidarias de formar familias y realizar sus legítimos anhelos.

En esta construcción de parentesco lo que define a las relaciones inter género, de manera mucho más pronunciada que las familias heterosexuales, son sus negociaciones y compromisos en el contexto de relaciones comunitarias.

El trabajo aborda la problemática de la homoparentalidad desde la perspectiva de género pues se busca indagar en el cómo y el qué negocian homosexuales y lesbianas para la reproducción y la crianza en contextos que trascienden la noción dominante de familia; la familia nuclear de pareja conyugal heterosexual.

En efecto, hombres y mujeres no heterosexuales requieren planear cada paso del proceso que lleva a convertirse en padre y/o madre ya que no hay nada "natural" en la paternidad y/o maternidad creada fuera de la hetero-norma. Para Judith Butler el parentesco no es necesariamente heterosexual y se basa en "una serie de prácticas que instituyen relaciones de varios tipos mediante las cuales se negocian la reproducción de la vida y las demandas de la muerte" (Butler, 2006: 150). Según esta autora las familias homoparentales representan una ruptura del parentesco tradicional que desplaza no sólo las relaciones sexuales y bilógicas del lugar central que ocupan en su definición, sino que "otorgan a la sexualidad un dominio separado del parentesco, lo que permite que un lazo duradero se pueda pensar fuera del marco conyugal y que se abra el parentesco a una serie de lazos comunitarios que no pueden reducirse a la familia" (Butler, 2006: 183). Las familias homoparentales son en definitiva proyectos reflexivos. 
Por cierto, la comunidad LGTBIQ (Lesbica-Gay-Trans-Bi-Intersexo-Queer) es parte del contexto socio-cultural y político en que está inserta la homoparentalidad y los lazos que se construyen dentro de esta alcanzan "límites que cuestionan la posibilidad de distinguir el parentesco de la comunidad" (Butler, 2006: 183).

Con todo, en muchas sociedades existen barreras estructurales que hacen del proyecto de hacer familia para las personas no heterosexuales un desafío prácticamente imposible.

En Chile actualmente si una pareja de hombres decide tener hijos no tiene más alternativas que dejar el país para hacerlo. Esto porque las leyes y el sistema de adopción comportan una serie de áreas grises que se traducen en una virtual discriminación hacia ellos. Por otro lado, puesto que ninguno de los dos puede embarazarse, el costo médico de tener un hijo en otro país para ellos bordea los US $\$ 75.000$. $^{1}$

El caso de las parejas de mujeres en el contexto chileno es distinto. Si ellas deciden seguir el camino de la adopción pueden hacerlo y de hecho existen casos en que se ha permitido la adopción a dichas parejas. Por cierto, este camino no está exento de problemas pues siempre la tuición legal le corresponde únicamente una de las dos. En el caso que opten por un hijo/a biológico, nuevamente una de ellas queda en desigualdad frente a la otra pues será la madre biológica quien goce de la tuición legal sobre los/as hijos/as (en Chile no existe el matrimonio homosexual a diferencia de otros países de la región como Argentina y Colombia). Además, no pueden hacer pública su opción sexual pues arriesgan perder la tuición de los hijos/as, como sucedió en el caso de la Jueza Karen Atala².

Cuando hombres y mujeres no heterosexuales optan por llevar a cabo una maternidad o paternidad biológica necesitan recurrir a personas del sexo opuesto. En estos casos dicha persona suele ser también no heterosexual.

La investigación sobre familias lésbicas ha establecido que ellas siguen distintas alternativas para hacer familia en relación con el donante de esperma; un donante desconocido; un donante conocido; un donante conocido y participativo (Herrera, 2005). Los varones pueden "arrendar" un vientre, que no siempre es una alternativa legal, o hacerlo por medio de una amiga, pero se sabe muy poco sobre estos proyectos de familia. El presente trabajo busca aportar conocimiento en este ámbito.

Por cierto, más allá de estas restricciones, el hacer familia homoparental, que puede o no implicar descendencia, se da además en el marco de la globalización. Los modelos de sociabilidad que se extienden a través de los mass media desde unas sociedades a otras abren mayores posibilidades a los hombres y mujeres de la comunidad LGTBIQ para realizar el legítimo anhelo de formar familias.

\footnotetext{
${ }^{1}$ Esta situación ha sido documentada por Televisión Nacional de Chile en su serie Happy Together, exhibida durante el año 2015, que retrata la convivencia de una pareja de hombres intentando convertirse en padres y cuyos protagonistas han participado en el presente estudio.

${ }^{2}$ Como es sabido a la jueza Atala le es revocada la tuición de sus tres hijas en mayo de 2004 en virtud de su opción sexual lésbica, vivida abiertamente.
} 
ISSN 0719-0417 / $106-127$

Este artículo presenta una contextualización del objeto de estudio (las relaciones de género emergentes en el contexto de la homoparentalidad) a partir de la desigualdad de género en el cuidado hoy en sociedades del cono sur y presenta la emergencia de una "nueva" paternidad. Luego se propone el estudio de "otra" paternidad en el contexto de la homoparentalidad. Se expone el estado de la cuestión en torno a un conjunto de temáticas centrales para la producción de saberes relativos al objeto de estudio; la homoparentalidad, el cuerpo reproductivo y el género, la paternidad trans.

Finalmente, se presentan los hallazgos empíricos y las conclusiones procedentes del análisis del material cualitativo recogido en el terreno.

\section{Objetivos del estudio}

Al nivel más general este trabajo tiene como objetivo aportar mayor espesor y precisión teórica a la definición de la categoría de género puesto que se requiere profundizar dentro de la definición aceptada del género como la construcción cultural de la diferencia sexual (Lamas, 2000), ya que esa definición se ha circunscrito dentro de lo heterosexual.

Para avanzar en dicha dirección, el presente trabajo se propone aportar, desde la evidencia empírica, argumentos que sustentan la centralidad del cuerpo y la procreación para la compresión del género y por ende de su definición.

En un nivel más específico este trabajo tiene como objetivo alimentar la discusión teórica sobre la igualdad y equidad de género en el contexto de la homoparentalidad, con una reflexión crítica sobre las relaciones de género, la sexualidad y el trabajo de cuidados para ayudar a actualizar dicha discusión y situarla más allá de los límites epistemológicos heteronormados.

\section{Antecedentes y contexto del estudio}

Como se ha dicho, el enfoque del presente trabajo se inscribe dentro del paradigma de género, es decir, dentro de la noción que lo masculino y lo femenino corresponden a construcciones sociales y que como tal comportan determinantes sociológicas, históricas, políticas e incluso sexuales.

Desde esta perspectiva se entiende que el género corresponde a lo que la cultura y la sociedad designan como comportamientos propios de hombres y mujeres, sobre la base de los cuerpos sexuados.

En dicho enfoque la familia tiene un papel central, ya que ha sido entendida como uno de los principales ámbitos institucionales dentro de los que se reproduce el orden social del género. 
La familia es donde se organiza la vida doméstica y por ende desde donde, a través de procesos de socialización primaria que permiten el aprendizaje de los roles sexuales, que por cierto incluye la maternidad y la paternidad, se producen y reproducen las inequidades entre hombres y mujeres.

Como se ha indicado en previas publicaciones los estudios sobre familia, maternidad y "paternidad en Chile a fines de los noventa y comienzos de la década del 2000 (Alméras, 1997; Valdés y Olavarría, 1998) revelan que los varones invierten mucho menos tiempo que las mujeres tanto en el cuidado de los hijos como en las labores domésticas" (Robaldo, 2015: 65).

Esta situación se mantiene más o menos constante hasta el presente a nivel global, como lo revela el Informe Global sobre Paternidad de 2015. (MenCare Advocacy, 2015)

Resultados similares muestra la investigación concerniente al tema en Argentina (Wainerman, 2007; Cosse, 2009), que señalan que aun cuando ya en los años setenta existía una mayor participación de los varones en la crianza y en el espacio doméstico, esta no se traducía en igualdad de condiciones para ambos sexos.

Las realidades que estas cifras obligan una lectura crítica. En este sentido, desde el paradigma del género se puede entender a la familia como un terreno de reproducción del orden sexual y de la dominación masculina. En efecto, la teoría feminista ha abonado enormes y valiosos conocimientos en esta materia toda vez que la noción de la división sexual del trabajo ha sido concepto de gran valor heurístico desde el siglo pasado.

Resulta entonces relevante producir conocimiento crítico mediante el estudio de prácticas de la crianza y los significados de las maternidades y paternidades. Dicho estudio debe enfocarse sobre los mecanismos y/o procesos a través de los cuales se reproduce o no la desigualdad de género a través de dichas prácticas y significados.

Los estudios de familia, género y masculinidades en la región se han planteado mayormente desde una perspectiva hetero-centrada, es decir no han trascendido el discurso heterosexual y esto se constata en cómo no han asumido la problemática de la paternidad y maternidad no heterosexual.

\section{Las familias homoparentales}

El común denominador de las familias homoparentales es que deben inventarse a sí mismas en mayor medida que las familias tradicionales. Weeks (2001) señala que, a partir de la experiencia de exclusión y marginación nacida del estigma, muchos no heterosexuales han construido relaciones de pareja más reflexivas. Weeks habla de "experimentos de vida" para referirse a aquellos espacios y relaciones cotidianas en los que homosexuales y lesbianas construyen dinámicas de pareja alternativas a partir de experiencias de vida que implican la exclusión de las formas hegemónicas del género y la familia. 
En el caso de las parejas no heterosexuales que crían, su construcción de familia es en cierto sentido una suerte de novedad histórica, que tiene eso si a sus propias familias de origen como un factor facilitador. En este sentido Robles señala:

"La aceptación de la vida familiar que gays y lesbianas han adoptado no parece estar estrictamente vinculada con el progresismo que los/as progenitores/as hayan podido evidenciar o no en sus juventudes-y que los haría más flexibles a lo diferentes-. Ello parece estar más relacionado con cierta capacidad de flexibilidad y adaptación a los cambios por parte de esos/as progenitores/as. Y ello no parece depender de un pasado de apertura a lo nuevo, sino de la mayor permeabilidad actual frente a lo que se presenta como novedoso" (Robles, 2016).

En este sentido y específicamente sobre la paternidad no heterosexual, Bigner y Jacobsen (1992) señalan que los padres gay, comparados con padres heterosexuales, incorporan un mayor grado de expresión emocional a sus prácticas de crianza y tienen menos propensión a comportarse según roles sexuales tradicionales, lo cual se traduce en una relación más nutricia con sus hijos/as.

Por cierto, estas parejas que crían también pueden reproducir códigos aprendidos de las parejas heterosexuales. El sentido de pareja monógama podría ser un ejemplo.

En relación con lo anterior, la crítica desplegada por los/las teóricas/os Queer sobre el ejercicio de la maternidad y la paternidad ha convertido estas prácticas en un terreno tanto de disputa de legitimidad como de acción política para personas y agrupaciones LGTBIQ, las que paulatinamente han avanzado en la igualdad de derechos en lo que respecta la formación de familias.

En tal sentido, Judith Butler ha hecho la pregunta sobre si el parentesco es siempre y necesariamente heterosexual y con eso aportado a iniciar una reflexión sobre qué significan desde una perspectiva de género la procreación, la reproducción y el parentesco (Butler, 2007).

Por cierto, estos aportes de la teoría queer y la teoría feminista tienen claros nexos epistemológicos entre sí y constituyen dos fuentes principales en la problematización de los esencialismos de género y su impronta en la sexualidad, en los arreglos de pareja y de familia, como en la reproducción.

Actualmente, la formación de familias homoparentales adquiere progresivamente un carácter global y actualmente en la región de América Latina se ha legislado en pro de dichas familias. Se destacan los casos de Argentina y más recientemente Colombia donde existe legislación que ampara la adopción de niños/as por parejas del mismo sexo.

La homoparentalidad transgrede un límite arraigado en las estructuras del lenguaje y la cultura que dice relación con la construcción de la realidad en términos binarios. En este marco la esfera de la reproducción indefectiblemente se entiende como procreación biológica entre macho y hembra y como reproducción cultural de un orden heterosexista. 
En efecto, a partir del principio de la procreación la norma heterosexual ha regulado a los saberes científicos sobre género e identidad sexual. Por ejemplo, para el Psicoanálisis el proceso de edipalización se resuelve "satisfactoriamente" cuando el individuo logra una identificación con un progenitor dentro del marco heterosexual, precedido y articulado en torno al binario de género.

\section{El cuerpo reproductivo}

El cuerpo ha tenido durante siglos el sustento de su "verdad" científica en la medicina y biología, pero en el marco de la modernidad este discurso ha terminado por propiciar la transformación del sentido monolítico del cuerpo, de la concepción que el sexo biológico, el género y la reproducción forman un todo en el que estos elementos están naturalmente unidos.

Según Butler (2015) los discursos de la ciencia sobre el cuerpo producen una poderosa verdad; que el sexo se puede definir en virtud de la posición relativa que cada uno ocupa en la vida reproductiva. La autora además afirma que las funciones reproductivas del hombre otorgan sentido a sus diferentes atributos de género, a la vez que las funciones reproductivas de las mujeres le dan sentido a la definición de mujer.

Dicho esquema es obviamente poderoso en nuestra cultura y prueba de esto es que cuando existen cuerpos que no son reproductivos ya sea por opción o por no contar con esa "capacidad".

La idea que la reproducción del cuerpo sexuado se encuentra al centro del orden de género da una vuelta de tuerca a la definición tradicional a la que estamos acostumbrados, el género como la construcción cultural de la diferencia sexual. Hay pues una pregunta previa: ¿Cómo o en virtud de qué se define la diferencia sexual? Una respuesta posible es que la diferencia sexual se define en virtud de la posición relativa de los cuerpos en relación con la procreación (Butler, 2015). En este entendido la noción del género tendría que plantearse más precisamente cómo la construcción social y cultural de los cuerpos reproductivos.

Según Butler (2015) hay que ir más allá de la descripción positivista de la materialidad del cuerpo y pensarlo en tanto campo de relaciones sociales, para lo que se hace necesario expandir el paradigma de la sexualidad más allá de las fronteras puestas por las definiciones determinadas por la reproducción sobre el cuerpo sexuado.

Los hallazgos del estudio de Herrera (2015) muestran como en la construcción del cuerpo reproductivo de sus entrevistados se cruzan la fertilidad y la virilidad, pues para estos varones lo natural es poder tener hijos, es decir ser fértiles. Esta construcción del cuerpo masculino como un cuerpo reproductivo implica para ellos, hombres infértiles, un sufrimiento que no pueden expresar pues consideran que su papel debe ser el de apoyar a sus parejas, quienes ellos consideran realmente sufren con los tratamientos médicos de la inseminación artificial o in vitro. 
La reproducción no solo tiene como resultado nuevos seres humanos, también ayuda a reproducir el binarismo del sistema sexo/genero. Una pregunta interesante radica en pensar las formas con que se coluden la heterosexualidad y el patriarcalismo para determinar cuáles son las expectativas sociales sobre el cuerpo masculino y la reproducción. Estas suelen ser un arquetipo masculino que corresponde al hombre blanco, heterosexual, con bienes, educado y urbano.

Pero simultáneamente y en oposición al orden de dominación masculina actualmente se manifiestan procesos globales de transformación de las identidades de género y de las prácticas sociales del parentesco que reflejan una lucha por los significados que denotan el cuerpo reproductivo y que por cierto se expresan en nuestras sociedades latinoamericanas.

Entre estos procesos son particularmente elocuentes las experiencias de vida da las personas trans-género. La reflexión en torno a la identidad de género trans como la parentalidad trans nos permite ver con mucha claridad cómo funcionan los mecanismos de naturalización en torno a la sexualidad, la identidad de género, la procreación y reproducción.

En tal sentido Silfen (2014) plantea que las personas transgénero que eligen ocupar sus órganos reproductivos biológicos para la reproducción nos obligan a cuestionar la autenticidad de los roles "naturales" de género, además de lo "natural" que pueda ser el binarismo sexo/genero. Para Silfen la reproducción transgénero es un acto de rebeldía total frente al binarismo de sexo/género. El objetivo de la deconstrucción en Silfen es poder sacar al género de la reproducción, lo que resulta relevante al menos para las mujeres trans pues la inhabilidad de reproducirse en tanto poseedor de un género que uno mismo ha definido, como es el caso de los cuerpos trans, es usado como significante de inautenticidad de género.

\section{La paternidad emergente}

Una de las autoras que describe el desarrollo de un modelo emergente de paternidad en América Latina es Isabella Cosse (2009), quien en su artículo La emergencia de un nuevo modelo de paternidad en Argentina revisa el desarrollo de dicho modelo en el transcurso de tres décadas, entre los años 50 y 70.

Mediante la revisión de material que refleja las pautas culturales de la sociedad argentina, como revistas, películas, libros, columnas periodísticas y series de televisión, la autora da cuenta de la transformación del modelo de paternidad desde un padre autoritario, distante y proveedor exclusivo hacia una figura cercana, afectiva e involucrada en la crianza.

Cosse señala que durante los años 50 la ciencia médica se hace parte del discurso que norma cuáles debían ser los parámetros dentro de los que debía desempeñarse la paternidad. En esta década se estimaba que la paternidad no podía tener un carácter instintivo, sino que debía ser el producto de la sociedad y la cultura. Para el modelo de paternidad difundido en esta etapa (entre un segmento social reducido que se suponía culto 
y de alto poder adquisitivo) la autoridad del padre debía ser el resultado de la confianza, el cariño y el respeto.

Hablando siempre sobre el desarrollo del modelo de paternidad emergente en Argentina Cosse señala que durante los sesenta se instala la perspectiva psicológica de la infancia que implica dejar de lado la evaluación moral de las conductas infantiles para evaluarlas según el contexto del desarrollo psicológico.

En ese marco se señala que la finalidad de una buena crianza era la estabilidad psicológica de los niños, para lo cual cobraron renovada importancia la autonomía y el rechazo a la violencia física. Durante estos años el modelo de la nueva paternidad adquirió creciente difusión en amplios segmentos del público y "para la tranquilidad de los padres se insistía en que las nuevas pautas no herían la virilidad, ni significaban que los padres reemplazasen a las madres en las tareas consideradas "naturalmente" femeninas". (Robaldo, 2015: 66).

En estos años lograron popularidad ciertos libros y talleres educativos que desde una noción psicoanalítica tradicional de los roles de género insistían en que la autoridad paterna ya no debía basarse en la imposición y la fuerza, sino en el diálogo y la comprensión (en forma concordante con las transformaciones modernas de la familia) en las cuales el padre podía compartir con la mujer el trabajo fuera del hogar y las responsabilidades políticas en la sociedad, pero esto no significaba que la figura del padre pudiese ser transferible (Cosse, 2009).

\title{
Como indica Robaldo:
}

\begin{abstract}
"Señala Cosse que a medida que se complicó el concepto de paternidad se identificaron ciertos riegos que conllevaba el ejercicio de la paternidad. El padre debía mantener el equilibrio en su desempeño entre las distintas demandas que implica su papel y no permitir la aparición de "deviaciones" (el término viene de la propia literatura de la época) en la formación del rol sexual de la prole, siendo las más inquietantes la homosexualidad y la delincuencia de los hijos varones.... Durante los setenta el modelo de paternidad por primera vez promueve que el padre traspase la división de roles de género de la domesticidad. Las revistas especializadas de esos años promovían que el padre tuviese la misma implicación en relación con los hijos que la madre. La importancia de la figura paterna ya no se apoyaba en las consecuencias peligrosas de su ausencia, sino en las influencias positivas de la paternidad activa y en las gratificaciones de la tarea en sí misma". (Robaldo, 2015: 67).
\end{abstract}

Por cierto, "la nueva paternidad ganó más terreno en el orden de los mandatos que en el de las prácticas. Sin embargo, más allá del problema de la incorporación a las prácticas cotidianas, las actitudes paternas del nuevo modelo comenzaron a quedar integradas en las auto-representaciones de ciertos padres". (Robaldo, 2015: 67).

Es interesante constatar que la construcción del padre también depende de la sexualidad y la subjetividad. Entre los jóvenes homosexuales chilenos por ejemplo la noción del padre en tanto autoridad no tiene mayor legitimidad, lo que se explica "porque la figura del padre 
para estos entrevistados en primera instancia aparece como lejana y silenciosa. En este sentido, el padre se vislumbra como un sujeto débil, cuya ausencia se da en términos no solo "reales" sino que también simbólicos". (Robaldo, 2015: 67).

\section{Homoparentalidad y la otra paternidad}

Si bien la paternidad se ha investigado también en Chile y otros países de la región (Olavarría 2001, Olavarría y Parrini 1999), dicha investigación no se ha dirigido a la experiencia de hombres no heterosexuales. Es relevante salir del cerco epistemológico de la heterosexualidad y avanzar en el estudio no de la nueva paternidad, sino que en la investigación sobre otras paternidades.

Para muchos de los jóvenes homosexuales antes mencionados la propia familia, que incluye a los padres, es la base para las labores de crianza porque de ella se desprenden los comportamientos que involucrarán el ejercicio de la paternidad. Al respecto cabe destacar la estrecha relación que mantiene uno de esto jóvenes con su padre, "marcada por la comunicación afectiva y la compañía, operando en gran medida como factor protector frente a un vínculo nocivo con la madre" (Robaldo, 2015: 67).

Por otro lado, estos jóvenes declaran que "las ganas de concretar la paternidad surgirían cuando se tiene pareja y comienzan a crearse planes de familia. Esto evidenciaría como el proyecto de vida de estos varones se relaciona con prácticas heteronormadas" (Robaldo, 2015: 66).

Por otro lado, Laguna (2015) señala "Los varones gays que acceden a los hijos, lo hacen en los intersticios de los imperativos biológicos, las restricciones sociales y el imaginario social construido en torno a la homosexualidad". Más aún, como señala Robaldo:

"Según Laguna los varones gays trastocan los patrones heteronormativos y desestabilizan algunos de los esquemas vinculados a la familia y a la crianza y cuidado al establecer relaciones filiales. Los varones gays, aunque sufren de la negativa social en relación con la paternidad, desean desarrollar arreglos parentales y prácticas de cuidado muy similares a las familias que conocen y en las que fueron criados, no obstante, la misma homofobia los impulsa a desapegarse de los modelos tradicionales de familia con lo que de manera inadvertida desestabilizan algunas de las concepciones vinculadas a esta última. Algunos de los prejuicios de los que habla Laguna, como por ejemplo que los varones no son capaces de procrear, criar ni educar niños/as, los podemos entender como mecanismos de naturalización de la masculinidad dominante que, a su vez, inscritos dentro de una representación heteronormativa de la masculinidad, convierten la paternidad homosexual en una amenaza literalmente de "fin de mundo", de fin de procreación de la especie. Sólo hay espacio para un imaginario del cuerpo masculino apto para la producción de las 
mercancías y la violencia, pero sin "futuro" para la producción de la vida" (Robaldo, 2015: 69).

Laguna (2015) añade "la homofobia ha creado al homosexual como un sujeto abyecto, un varón estéril que no desea reproducirse y no es capaz de criar infantes... Dado que se ha considerado a los homosexuales como sujetos estériles, por lógica se estima que es imposible que conformen una familia" (Laguna, 2015). El autor agrega que estos fenómenos sociales, así como las prácticas homofóbicas, aunados a que no existen modelos de parentalidad gay, han hecho que muchos varones gays no consideren ni la crianza y cuidado de infantes ni la configuración de un arreglo parental como una vía posible de desarrollar su vida: "nosotros estamos incluso más prejuiciados que los propios heterosexuales"

Además, los padres gay mexicanos buscan "proteger" a sus hijos por medio de "burbujas" $y$ "fachadas" que mantienen en secreto la naturaleza de la familia, manteniendo alejado los prejuicios y perjuicios que implica un medio homofóbico.

\section{Estrategia metodológica}

La estrategia metodológica del estudio tomó en cuenta los requisitos establecidos para la realización el trabajo final del Master, en particular el marco de tiempo provisto para su realización. Además, contempló la necesidad que la investigación incluyera trabajo de campo, y posteriormente el tratamiento de datos, su análisis y la preparación de un informe final.

Un primer desafío fue definir cuanto tiempo se destinaría al trabajo de terreno y la cantidad de información factible levantar en dicho tiempo.

Se opta en consecuencia por un diseño metodológico de estudio de caso en el que se trabaje con una sola familia en profundidad, abarcando un espectro diverso de temáticas durante el curso de las entrevistas con sus integrantes. Como señala Yacuzzi (2005: 3) "A través de un diálogo organizado sobre una situación real, el método (estudio de caso) utiliza la experiencia para la transmisión del conocimiento".

Este enfoque es apropiado para el trabajo propuesto, además, pues permite estudiar preferentemente temas contemporáneos y emergentes, respondiendo en profundidad a las interrogantes de dicho estudio.

En el marco de este diseño metodológico y para definir la extensión de las entrevistas a realizar se operó con un criterio de saturación de la información.

Se realizaron entrevistas en profundidad dentro del grupo familiar para analizar las dinámicas de géneros, además de usar el material de entrevistas a los miembros de la familia registrados en el docureality Happy Together, transmitido por Televisión Nacional de Chile durante el año 2015. 


\section{El caso de estudio}

Puesto que la investigación aborda las dinámicas emergentes de hacer familia entre personas no heterosexuales para estudiar la equidad de género entre hombres y mujeres, el caso elegido para el estudio reúne a mujeres y hombres, de orientación sexual no heterosexual.

Se trata de un caso que reúne características muy interesantes desde un punto de vista multicultural y que refleja las dinámicas presentes en el "hacer" familia (discutiremos en el siguiente apartado la noción del parentesco como performatividad según lo define Judith Butler) dentro de un contexto de globalización.

Las personas entrevistadas construyen familia sobre un periodo de muchos años y mucha distancia muchas veces, entrelazando sus relaciones de parentesco con la amistad y el activismo político. Como hemos señalado al principio del documento, el parentesco es estos casos no puede reducirse a la familia pues sus alcances cuestionan la posibilidad de distinguir entre comunidad y familia.

Como se ha dicho, una arista de este caso fue conocida por el público chileno a través de un programa de televisión abierta, del género docureality, que se exhibió durante el año 2015. El programa titulado Happy Together muestra el proceso que atraviesa una pareja de hombres que buscan tener un hijo. Julio, uno de estos hombres, es a quién hemos entrevistado para conocer su proceso como papá de Levi, de 11 años, junto a Mindy su amiga y madre no biológica del niño.

\section{Análisis}

Judith Butler plantea que la homoparentalidad implica un sentido radicalmente distinto del parentesco. Lo plantea como un "hacer" que no refleja necesariamente una estructura anterior. Así, el parentesco lejos de suponer una heterosexualidad fundante que pone como condición de ingreso del individuo a la cultura el tabú del incesto y el proceso de edipalización (en tanto mecanismos diferenciadores de género que reproducen el orden heterosexual y la identidad de género diádica), es una práctica representada, una performatividad (Robaldo, 2011: 173).

La idea que el parentesco se "hace" nos ofrece una salida a sus prácticas hegemónicas y heteronormadas, lo que según Butler:

"nos permitiría evitar que una estructura de relaciones hipostatizada se oculte detrás de los actuales acuerdos sociales y nos permitiría considerar el cómo los modos de hacer, pautados y performados, hacen funcionar a las categorías de parentesco y se convierten en los medios a través de los cuales las categorías experimentan una transformación y/o desplazamiento" (Butler, 2006: 178) 
ISSN 0719-0417 / $106-127$

Este marco nos permite comenzar a interpretar los relatos de los entrevistados.

\title{
La trayectoria a la Paternidad
}

La siguiente es la biografía de Julio tal como él mismo la relata brevemente al comienzo de la entrevista.

\begin{abstract}
"Mi biografía es que yo nací en Brasil, hijo de mi mamá a los diecinueve años de edad, y mi papá que tenía veinte o veintiuno. Nunca fue violento con mi mamá, hasta el día después de que se casaron, y llegaron a la casa del matrimonio y mi papá empezó a ser súper violento con mi mamá, nosotros pasamos nuestros primeros años de vida sufriendo bastante, diré que mi mamá protegiéndonos para que él no nos matara, principalmente.

Y eso en el sur de Brasil, una ciudad que se llama Paraguaná Curitiba, y a los cuatro o cinco, mi mamá se divorció de mi papá y huimos a Río, para que nosotros pudiéramos huir de la violencia que estábamos viviendo con mi papá. Y vivimos ahí hasta los catorce o quince, y mi mamá era secretaria de "Bella", una empresa de champú. Y yo estudiando y cuidándome básicamente, porque ella trabajaba de ocho hasta las siete de la tarde, y yo estudiaba hasta las doce y después tenía que cuidarme, cocinarme para mí mismo, etc.
\end{abstract}

Después a los catorce o quince nos fuimos a Estados Unidos, y fuimos como inmigrantes ilegales como por tres años, de "nana", en San Francisco, pues mi mamá conoció a mi padrastro Josh O'Brian, súper irlandés de Massachusetts, de Boston. Y allí empezó como una nueva etapa de vida, donde ellos estaban juntos, tuvieron a mis hermanos.

Tengo dos hermanos biológicos, y un hermano que es un primo mío, hijo del tío, hermano de mi mamá obviamente que era súper pobre en Brasil, entonces mi mamá trajo el hermano mayor de tres hermanos para que pudiera tener aquí trabajo, y poder ayudar a sus hermanos. $Y$ al mismo tiempo yo estudié sociología y estudios feministas, y de ahí empecé con mi vida laboral gringa, en San Diego, Nueva York, San Francisco, estuve trabajando en la costa básicamente. Y con interés en políticas sociales, "Social Justice" y activista, de plano general. Temas que tienen que ver con personas más vulnerables, pobres, migrantes, etc.

Después fue alineándome más con el tema del LGBT, y a los treinta decidí regresar a la universidad para hacer una maestría en Políticas Públicas y Administración Pública, y después mi mejor amiga, Mindy, me hizo prometer que yo viajaría de verdad, como yo siempre había dicho, y yo terminé mi maestría y empecé a viajar alrededor del mundo por dos años, y cuando pasé por Chile, fui a bailar una noche en Fausto. No sé si conoces el Fausto, el bar, conocí a mi marido Juan Pablo, y conocí este gran y diverso, y progresista país que se llama Santiago, se llama Chile".

Vemos que en la historia temprana de Julio la violencia de género es un hito, remarcado por la situación crítica que enfrentan él y su madre al tener que "huir" hacía otra ciudad. Este momento marcara la trayectoria de su biografía toda vez que él y su madre forman una nueva familia y luego emigran a otro país, a otra cultura, donde por la fuerza de los hechos Julio se hace responsable de sí mismo y desarrolla un sentido de autonomía desde una edad temprana.

${ }^{3}$ El término "nana" en Chile hace referencia una trabajadora doméstica. 
Sin duda el contexto socio-cultural y político de San Francisco ayuda a definir sus intereses intelectuales, los que lo orientan a estudiar sociología y feminismo en la universidad, época en que iniciará además su activismo gay, lo que su vez define su trayectoria laboral en el campo de la justicia social, como él la define.

En este contexto Julio conoce a Mindy, una mujer estadounidense de credo judío, junto a la cual desarrolla una estrecha complicidad a partir de su "salida" como gay, pues como dice él, "yo salí del closet con ella, y ella salió del closet conmigo.... Y diría que ahí fue, como podríamos decir, su política y mi política, y fuimos activistas del LGBT, y luchamos mucho por distintos temas de derechos humanos de LGBT".

Tal es la complicidad entre Julio y Mindy en esta etapa que él habla de un co-construcción identitaria, "nosotros co -desarrollamos...nuestra identidad LGBT, ya sea lesbiana y gay". Lo anterior muestra como durante este tiempo los lazos que crean entre ambos son profundos y los vuelven parte de una misma comunidad.

Más tarde, a instancias de Mindy, Julio emprende un "viaje por el mundo" parando en Chile donde conoce a Juan Pablo, con quién más tarde contrae matrimonio. Por cierto, Julio y Juan Pablo se casan en Estados Unidos pues en Chile no existe una legislación robusta que proteja los derechos de las minorías sexuales, una situación que remarca Julio cuando dice en un tono irónico que Chile es un "gran y diverso, y progresista país" al final de su relato biográfico.

\section{La decisión de "cerrar el triángulo".}

Julio dice haber sido muy influenciado por dos amigos de credo judío, Spencer e Ina, en su tiempo de estudiante de secundaria, de hecho, él consideró convertirse al judaísmo durante el periodo universitario. Es así como Julio conoce a Mindy en el centro de alumnos judío. Este hito es relevante en la trayectoria de Julio hacía la paternidad pues él dice, "para mí es una de las cosas no negociables... que cualquier ser humano que trajera al mundo, tendría que crecer como judío". En este sentido Mindy es consustancial al proyecto de Julio de ser papá.

Es Mindy quien le propone por primera vez ser papá a Julio cuando él tiene 20 años, en medio de una marcha estudiantil. jJulio relata, "ella dice, para que sepas, cuando un día yo decida tener un hijo tú vas a ser el donante y yo, así como waa!! Ok".

Tras esto no se habló mucho más más del tema, hasta que 15 años después. Por solicitud de Mindy el acuerdo se concretó cuando ella estaba viviendo con su pareja, Melissa, en Washington DC y Julio terminaba su Maestría. En ese momento Julio, Mindy y Melissa inician un proceso de tres años hasta que nace Levi.

Entonces, aun cuando es Mindy quien decide primero que quiere tener un hijo con Julio como donante, a dicho plan se integra años después Melissa, quien además ha forjado una relación como amiga de Julio durante años. Al respecto Julio señala "yo también analicé, el 
Revista Punto Género N.ำ 9. Junio de 2018

ISSN 0719-0417 / $106-127$

hecho de que Mindy coexistía con Melissa, como una cosa positiva. Yo probablemente no habría dicho sí a la experiencia de tener a Levi si yo no hubiera estado de acuerdo con la persona que Melissa era, y conocerla de verdad fue conocerla por ocho años, antes de hacerlo".

En consecuencia, se adopta la estrategia de "cerrar el triángulo" y la familia se estructura con Julio y Melissa como los padres bilógicos y con Mindy como la madre adoptiva. De esa forma el vínculo de cada adulto con Levi es resguardado ante una separación, tal es la confianza que hay entre Mindy, Julio y Melissa.

Más tarde Mindy y Melissa efectivamente se separan y al respecto Julio dice "tuvieron un divorcio horrible, horrible, horrible, pero para Levi, Melissa y Mindy coexistirán para siempre, porque él existe y nosotros creamos el triángulo a propósito, este triángulo siempre fue definido basado en el bienestar de Levi".

En definitiva, Julio dice "nos prometimos a nosotros mismos, antes de hacer a Levi, que las dos cosas que iba a tener en la vida, no importara que pasara, iba a ser amor y honestidad, él siempre iba a saber de dónde vino, y porque vino, etc., y nosotros siempre íbamos a estar dedicados a él primero, antes de cualquier cosa, y así ha sido su crecimiento".

\section{La voluntad de ser madre...biológica}

El primer tema de negociación entre Julio, Meissa y Mindy antes de someterse al tratamiento médico que llevó al nacimiento de Levi fue si acaso tener o no un "bio-child" (niño biológico), o si era preferible adoptar un hijo/a. Julio era partidario de la segunda opción.

Hubo un periodo de seis meses en que debatieron el tema, tras lo cual primo la empatía de Julio con las dos mujeres. Julio señala que en un momento Mindy fue bastante no negociable y dijo: "mira es simple, somos mujeres y necesitamos tener un hijo en nuestros cuerpos, si tú no eres el donante encontraremos a otro, queremos tener la experiencia de la maternidad desde el principio". "Y eso fue lo que me convenció, como sí, entiendo, como si yo fuera una mujer, yo soy una persona muy corporal, muy conectada con mi cuerpo" dice.

Julio, Mindy y Melissa recurrieron a tres métodos para que esta última se embarazara. Los primeros dos, inseminación artificial y semen freso (a diferencia de congelado), no dieron el resultado esperado, pero si la inseminación in vitro. Inicialmente Melissa quedo embarazada de gemelos, pero uno de ellos no sobrevivió el primer trimestre del embarazo.

\section{Ser padre sin poder.}


Julio pone en énfasis en que la decisión de convertirse en donante para Melissa y Mindy se enmarca en una amistad de 15 años con esta última, él dice "teniendo o no teniendo a Levi, Mindy es como mi familia".

Para Julio la confianza de ser donante de Mindy estaba fundamentada también en que se trata de "una mujer que tiene una política de convivencia, de derechos humanos, progresista, social, que yo ya conocía, entonces para mí la decisión de ser donante... iba a ser para un ser humano que iba a venir crecer, en una familia que yo ya estaba súper alineado con todo lo que tenía que ver con eso". Es decir, la construcción de familia en este caso también tiene un trasfondo político en que el vínculo de confianza para formar familia entre estas personas pasa por la coincidencia de sus convicciones políticas.

Desde la experiencia más personal Julio dice que sus hermanos menores también fueron parte del fundamento de su decisión de ser papa. Señala es un hito en su vida el haber cortado el cordón umbilical de cada uno de ellos durante sus nacimientos, cuando él tenía 17 y 22 años respectivamente.

Julio dice "mi vida siempre ha sido un poco definida de manera positiva sobre el hecho que yo soy un tío ${ }^{4}$ o sea, tío de mis hermanos, y toda mi vida mis papás fueron súper claros que yo estaba en el testamento como la persona que iba a recibir mis hermanos si algo pasaba con ellos".

En este contexto de confianza Mindy plantea a Julio, y su vez él acepta, ser papá como donante conocido, es decir que el hijo/a de ambos sepa que él es padre bilógico, pero sin ningún poder para decidir sobe asuntos de la vida del futuro hijo.

El hecho es que Julio estructura su paternidad en base a las necesidades de Levi y enfatiza que lo importante es "estar ...presente en la medida que tiene sentido para que él (Levi) crezca bien".

Pero agrega "sin embargo, mi único requisito, mientras yo estaba firmando todas las cosas para que sea adoptado por Mindy, por que la madre biológica es Melissa, es que yo necesito ser la persona que lo reciba en caso de que ustedes (Mindy y Melissa) se mueran. Y ese es el contexto de como nosotros existimos". Lo anterior hace eco de lo que Julio aprendió en su experiencia de asumir a sus hermanos.

Si bien Julio se plantea el proyecto de su paternidad desde el lugar del donante conocido sin poder de decisión sobre la vida de su hijo y reconoce a Mindy y Melissa como los adultos determinantes en la vida de Levi, a la vez él asume la responsabilidad de haberlo traído al mundo y de lo que dicha decisión podría conllevar para Levi entrada la adolescente, por el estigma quizás.

Julio dice "yo diría que ese fue como un momento de la preexistencia de Levi donde este rol de papá se tornó algo relevante para mí, al pensar el día que él nació que quizás yo hice

\footnotetext{
${ }^{4}$ Además de denotar un vínculo de parentesco consanguíneo, en la cultura chilena el término tío puede identificar a un adulto que es reconocido como significativo en la vida de un menor. También denota respeto por la autoridad de dicho adulto.
} 
Revista Punto Género N.ำ 9. Junio de 2018

ISSN 0719-0417 / $106-127$

algo que fue tan conectado con la paternidad que podría significar que él me odie (algún día). Esta emoción de pensar que él podía odiarme fue la emoción más cercana en el rol de papá biológico de verdad".

\section{"La potencia de los genes"}

Julio mantiene una relación con Levi separados por la distancia entre Santiago de Chile y Washington DC. Mantiene contacto permanente con Levi vía Skype, pero tiene un compromiso "inequívoco" con Mindy y Melissa de encontrarse con su hijo "cara a cara" y de hecho se reúnen un par de veces al año.

Más aún, Julio señala que no sintió el "poder de padre" hasta después que nació Levi y comenzó a mostrar su personalidad, él dice "el poder de padre vino después de que nació, no antes" ...y.... "me sorprendió a un nivel inimaginable, el hecho que Levi es yo. Es igual."

\section{El cuestionamiento de ser un padre sin poder}

Julio explica que si bien él no tiene poder sobre las decisiones que afectan a Levi, sí tiene influencia. El grado de influencia la han negociado con Melissa y Mindy, siempre en función de las necesidades de Levi. Sin embargo, el difícil proceso de divorcio entre Mindy y Melissa obligo a Julio a intervenir más allá de lo establecido.

Durante el divorcio Mindy y Melissa viven junto a Levi en Washington DC. Julio, quien vive en Santiago de Chile, los visita y ve que la separación afecta muy fuertemente en lo emocional a Levi, lo que se expresa a través de comportamientos regresivos agudos.

Para Julio la situación se vuelve insostenible, dice "yo diría que en general yo estaba súper cómodo con esta falta de influencia y poder.... el momento que más me he cuestionado este rol que yo decidí tener antes que Levi existiera en el mundo fue cuando las chicas estaban en su peor momento de relación y yo encontré que ellas estaban viviendo una vida de mujeres que se odiaban, que estaba afectando mucho a Levi y yo tuvo que intervenir $y$ tuve que decir ustedes resuelvan sus problemas porque este niño existe".

En este momento Julio se cuestiona el no contar con poder de decisión sobre la vida de su hijo. Dice "Yo iba de vacaciones a visitarlo, pero yo me fui un par de años muy mal, porque estás mujeres estaban viviendo esta experiencia y este niño lo estaba pasando tan mal, y me preguntaba cuál es mi rol y mi responsabilidad... ahí viene parte de este proceso donde yo más cuestioné mi rol de papá... y ahí es cuando yo me pregunté si hice una decisión buena de tener tan poco poder, de no poder influenciar, de no poder tomar decisiones porque yo veía que todos lo estaban pasando mal". 
Revista Punto Género N.ำ 9. Junio de 2018

ISSN 0719-0417 / $106-127$

\section{Hacia el futuro}

Durante la visita en el 2015 de Mindy y Levi a Santiago, retratada en la serie Happy Together", ella declara que Julio "es la persona que está ahí, él tiene un rol muy especial, siempre lo ha tenido, incluso antes de Levi hemos tenido un entendimiento sobre como negociar nuestra vida, la vida de Levi, donde él vive, donde nosotros vivimos y estar presente".

Para Mindy la decisión de Julio de ser el padre bilógico no tiene necesariamente que ver con convertirse en un padre efectivo, ella dice que ser un verdadero padre (parent) "tiene que ver con estar presente todos los días en la vida de un niño y ser la persona que está ahí para los mejores momentos y los más oscuros, en todo momento".

Según Mindy Julio no cumple un rol paterno y hemos visto que, al menos no un sentido convencional, eso es cierto. Pero ella agrega que Levi sabe que "No hay un Levi sin un Julio".

Julio por su parte expresa que "Mindy ha sido clara que yo necesito vivir al lado de ella". Para Julio la posibilidad de trasladarse junto Juan Pablo a vivir a Washington DC es muy real, es algo que han conversado y frente a lo cual se están organizando.

Julio se plantea plenamente desde el ser y el estar de la paternidad, dice "yo diría que hoy a los 11 (de Levi), yo puedo ofrecer el 50\% o 60\% de estabilidad (para Levi), yo todavía tengo que tener cuidado porque yo soy el adulto y tengo que ofrecer más de lo que él pida, pero yo imagino que en los próximos dos o tres años yo sigo creando este mundo donde él tiene muy claro quien yo soy y como soy, para que sepa quién soy o para que yo sirvo en su vida." En definitiva, él hacer paternidad de Julio es un proyecto, una trayectoria construida constantemente desde las necesidades de Levi, donde las decisiones de ese hacer son compartidas con Mindy y Melissa.

Julio dice "yo le pregunto (a Levi) si sabe que lo amo y él dice sabe que sí, que sabe que yo estaré para lo que necesite y que la mamá le dice lo mismo y que él ya sabe eso, que tiene más que claro que todos lo aman, entonces lo que importa es que lo tiene claro". Vemos que Julio se plantea desde los afectos frente a Levi y lo hace desde las necesidades de su hijo, con lo que construye una paternidad emocional.

Podemos pensar estos hallazgos desde lo que plantea Anne Cadoret (2003) en su libro Padres como los demás: homosexualidad y parentesco, sobre cómo las parejas homosexuales en Francia intentan dar coherencia a una identidad familiar atendiendo a dos cuestiones: por un lado, la importancia de lo biológico como fundamento de la familia y por otro la adecuación entre pareja conyugal y pareja parental.

${ }^{5}$ El programa mencionado se encuentra en el siguiente link: https://www.youtube.com/watch?v=KPFw2ceiV-w 
ISSN 0719-0417 / $106-127$

Vemos que para Mindy y Melissa en tanto pareja, efectivamente se da lo primero, la importancia de lo biológico como fundamento de la familia, al inicio y durante los primeros años de crianza de Levi. Sin embargo, hoy no se da una pareja conyugal entre ninguno de ellos. Respecto de lo segundo, también se disloca el orden de pareja parental al estar presente Julio. Se trata más bien de un trio parental.

\section{Conclusiones}

Es posible establecer a partir de los hallazgos del presente estudio la emergencia de relaciones de género más igualitarias en el hacer parentalidad entre hombres y mujeres no heterosexuales. Esto se expresa como un proceso reflexivo de negociaciones, decisiones y opciones en el que se embarcan estas personas en un contexto de homoparentalidad.

Si bien son Mindy y Julio quienes primero acuerdan traer un hijo al mundo, es decir establecen un acuerdo procreativo, este acuerdo luego se traduce en un programa o estrategia procreativa que incorpora a Melissa. Dicho programa procreativo va a requerir un acuerdo de vida que en lo central implica la estrategia de "cerrar el triángulo". Como vimos esto consiste en establecer relaciones formales de parentalidad que protejan el vínculo de Levi con los tres adultos significativos en su vida, frente a una eventual separación entre Melissa y Mindy.

La estrategia de cerrar el círculo se condice con el contexto comunitario en que las personas estudiadas hacen familia. En efecto, el caso de estudio muestra que el parentesco no heterosexual se hace mediante vínculos afectivos y de confianza cultivados que no se reducen a lo familiar tradicional. Es decir, se hace familia no sólo desde la consanguinidad y de la conyugalidad, sino que dentro de un contexto comunitario común.

Podemos afirmar que el hacer familia entre Mindy, Melissa y Julio no antepone una estructura de parentesco consanguínea con sus implicancias de patrilinalidad, más bien plantea la experiencia de la parentalidad desde el reconocimiento y la legitimación de la corporalidad femenina. Además, el hacer familia se plantea desde los afectos hacia Levi y desde sus necesidades como hijo, con lo que, desde la arista del vínculo entre Julio y Levi, se hace una paternidad emocional.

Esta paternidad emocional, como se ha señalado, constituye una re-significación de la paternidad que denota un cambio desde un modelo de paternidad tradicional y hegemónica, representada socialmente por el rol del proveedor económico y la autoridad de la familia, hacia prácticas y sentidos que valoran la afectividad, la participación en el cuidado y la comunicación con los hijos/as.

En palabras de Julio cuando se refiere a su experiencia de identificación con Levi, la paternidad emocional se vive como un "poder de padre". 
Revista Punto Género N.ำ 9. Junio de 2018

ISSN 0719-0417 / $106-127$

Los hallazgos del presente caso de estudio muestran evidencia para concluir que las maneras de hacer familia homoparental se han complejizado desde los hallazgos de la investigación a comienzos de la década del 2000.

\section{Bibliografía}

Alméras, Diane (1997): Compartir las responsabilidades familiares:una tarea para el desarrollo. Séptima Conferencia Regional sobre la Integración de la Mujeren el Desarrollo Económico y Social de América Latina y el Caribe (pág. S/N). Santiago de Chile: CEPAL.

Arriagada, Irma (2007): Familias y políticas públicas en América Latina: Una historia de desencuentros. Santiago de Chile: Comisión económica para América Latina y el Caribe (CEPAL).

Bigner, Jerry \& Jacobsen, R. Brooke (1992;23): "Adult responses to child behavior and attitudes toward fathering: gay and nongay fathers". Journal of Homosexuality, (3) pp.99-112.

Bourdieu, Pierre (2000): La dominación masculina. Barcelona: ANAGRAMA.

Butler, Judith (2002): Cuerpos que importan: Sobre los límites materiales discursivos del "sexo". Buenos Aires: Paidos.

(2006): Deshacer el género. Barelona: Paidós.

(2007): ¿El parentesco siempre es de antemano heterosexual? en Deshacer

el género. Barcelona: Paidós, pp. 149- 187.

(2015): "Cuerpos que aún importan". Conferencia en UNTREF,

Organizada por la Red Interdisciplinaria de Estudios de Género, 16 de septiembre.

Cadoret, Anne (2003): Padres como los demás: homosexualidad y parentesco. Barcelona: Gedisa.

Cosse, Isabella (2009): La emergencia de un nuevo modelo de paternidad en Argentina (1950-1975). Estudios Demográficos y Urbanos, vol. 24, núm. 2, mayo-agosto, El Colegio de México, pp. 429-462.

Cultura Salud/eme. (2011): Encuesta IMAGES Chile. Santiago: Cultura salud/eme.

Haraway, Donna (1988): Situated Knowledges: The Science Question in Feminism and the Privilege of. Feminist Studies, Vol. 14, No. 3. pp. 575-599.

Harding, Sandra (1987): Is there a a Feminist Method? Bloomington/ Indianapolis: Indiana University Press. 
Revista Punto Género N.ำ 9. Junio de 2018

ISSN 0719-0417 / $106-127$

Herrera, Florencia (2005): Familia y maternidad: sangre y cuidado en mujeres lesbianas. En X. Valdés, \& T. Valdés, Conservadurismo y trasgresión en Chile: reflexiones sobre el mundo privado. Santiago: FLACSO / CEDEM.

Herrera, Florencia (2015): Los hombres siempre adoptan: intertilidad y reproducción desde la perspectiva masculina. Actas del V Coloquio Internacional sobre Estudios de Varones y Masculinidades, (pág. S/N). Santago de Chile.

Hochschild, Arlie (1989): The second Shift: Working Families and the revolution at home. New York: Penguin Books.

Laguna Maqueda, Oscar (2013): Vivir Contarcorriente. Arreglos parentales de varones gay en la ciudad de México. México: Librero de la administación pública.

(2015). Arreglos parentales de varones gay en la ciudad de méxico: entre la parternidad negada y la transformación imprevista. Actas del V Coloquio Internacional de estudios Varones y Masculinidades, (pág. S/N). Santiago de Chile.

Lamas, Marta, (2000): La construcción cultural de la diferencia sexual, PUEG, México. Porrúa.

Lara-Quinteros, Rodrigo, \& Avendaño, María Francisca (2015): Vínculo padre-hijo: un análisis desde el itinerario biográfico de varones jóvenes no heterosexuales. Actas del $V$ Coloquio Internacional de Estudios sobre Varones y Masculinidades, (pág. $\mathrm{S} / \mathrm{N})$. Santiago de Chile.

Libson, Micaela (2010): Parentalidades gays y lesbianas: una mirada sobre la discriminación y la exclusión. Cuadernos del Inadi, (N²) Agosto S/N p.p.

MenCare Advocacy (2015): State of the World's Fathers. Washington, DC: Promundo, Rutgers, Save the Children, Sonke Gender Justice, and the MenEngage Alliance.

Olavarría, José (2000): Ser padre en Santiago de Chile. En N. Fuller (Ed.), Paternidades en América Latina (pp. 129-173). Lima: Pontificia Universidad Católica del Perú, Fondo Editorial.

Olavarría, José y Parrini, Rodrigo (1999). Los padres adolescentes, hombres adolescentes y jóvenes frente al embarazo y nacimiento de un/a hijo/a. Antecedentes para la formulación y diseño de políticas públicas en Chile UNICEF - FLACSO.

Robaldo, Marcelo (2011): "La homoparentalidad en la deconstrucción y reconstrucción de familia. Aportes para la discusión". Revista Punto Género, (№1) pp. 171 - 183.

(2015): "Aportes en torno a la paternidad y el cuerpo reproductivo masculino a partir de los hallazgos de tres estudios sobre varones y cuidados en Chile y México". Revista Punto Género, (№ 6) pp. 61 - 72.

Robles, Claudio (2016): Familias y homoparentalidad. Buenos Aires: Espacio. 
Revista Punto Género N.ำ 9. Junio de 2018

ISSN 0719-0417 / $106-127$

Sandoval, Mary Luz (2002): Pierre Bourdieu y la teoría sobre la dominación masculina. Revista Colombiana de Sociología, Vol VII No. 1 pp. 55-73.

Silfen, Ilyssa (2014): The reproductive body: Exploring reproducction beyond gender. City University of New York: Disertación y Tesis de Magister.

Valdés, Teresa, \& Olavarría, José (1998): Masculinidades y equidad de género en América Latina. Santiago de Chile: Flacso Chile.

Wainerman, Catalina (2007): Conyugalidad y paternidad ¿Una revolución estancada?. En M. A. Gutiérrez, Género,familias y trabajo: rupturas y continuidades. Desafíos para la investigación política (págs. p.p.179-222). Buenos Aires: CLACSO.

Weeks, Jeffrey (2001): Same sex intimaces: families of choice and other life experiments. Londres: Routledge.

Yacuzzi, Enrique (2005): El estudio de caso como metodología de investigación: teoría, mecanismos causales, validación. CEMA Working Papers: Serie Documentos de Trabajo. $n^{\circ} 296,1-37$. 